\title{
Biogeografia de formações vegetais: condicionantes de um encrave vegetacional (Campo do Veludo). Parque Estadual do Rio Turvo, Barra do Turvo, SP
}

\author{
Biogeografía de formaciones vegetales: condiciones de un \\ enclave de vegetación (Campo do Veludo). Parque Estatal del \\ Rio Turvo, Barra do Turvo, SP
}

\section{Biogeography of plant formations: conditions of enclave vegetation (Campo do Veludo). Rio Turvo State Park, Barra do Turvo, SP}

\author{
Gustavo Luis Schacht \\ gustavo.geografo@hotmail.com \\ Pós-graduando em Geografia - Universidade de São Paulo
}

\begin{abstract}
Resumo: O Parque Estadual do Rio Turvo (PERT) localiza-se no extremo sul do estado de São Paulo. Nesta região protegida, encontra-se o Campo do Veludo, uma formação fisionômica e floristicamente diferente da flora dominante. A espécie predominante no local é a forma nanificada de Psidium cattleianum, com até 1,40 metros de altura. Este estudo teve como objetivo levantar dados florísticos e pedológicos da área e propor uma explanação para sua presença no local. Desta forma, depreendeu-se que a formação do Campo do Veludo apresenta grande controle edáfico por solos quartzarênicos e espodossólicos e sugere-se sua classificação como Relíquia/Encrave de vegetação nanificada sobre Quartzito. Desta maneira sustentamos a hipótese de que o Campo do Veludo pode ser classificado como uma relíquia vegetal resultante de alterações paleoclimáticas recentes, somado às condições pedológicas e geomorfológicas locais.

Palavras-chave: Biogeografia ecológica. Sphagnum. Relictos. Vale do Ribeira.
\end{abstract}

Resumen: El Parque Estatal del Río Turvo (PERT) se encuentra en el extremo sur del estado de São Paulo. En esta región protegida se encuentra el Campo de Veludo, una formación fisonómica y florística diferente de la flora dominante. La especie predominante en la zona es el Psidium cattleianum enanizada hasta 1,40 metros de altura. La presente investigación tuvo como objetivo presentar datos florísticos iniciales y de suelo del área y proponer la motivación para su permanencia en este sítio. Así pues, parece que la formación del Campo do Veludo presenta gran control edáfico, y se sugiere su clasificación como Relicto / Enclave enanizado de vegetación en cuartzito. Así sostenemos que se trata de una reliquia vegetal resultante de los cambios paleoclimáticos recentes además de las condiciones pedológicas y geomorfológicas locales.

Palabras Clave: Biogeografía ecológica. Sphagnum. Relictos. Valle del Ribeira.

Abstract: The RioTurvo State Park (PERT) is located at the southern limit of the state of São Paulo. This protected region is Campo do Veludo, one physiognomic and floristic different formation of the dominant flora. The predominant species at the site is the 
nanified Psidium cattleianum up to 1.40 meters in height. This study aimed to raise initial floristic and soil-area data and propose an explanation for this remaining. Thus, it appears that the formation of the meadow presents large edaphic control, and it is suggested its classification as Relict / Enclave of nanno vegetation on Quartzite. So, we support the hypothesis that Campo do Veludo is relic vegetation that results both from recent palaeoenviromental changes as well local pedological and geomorphological conditions.

Keywords: Ecological Biogeography. Sphagnum. Relicts. Ribeira Valley.

\section{INTRODUÇÃO}

Ao observar-se uma paisagem, rapidamente é possível perceber a importância da visão geográfica, e da análise das diferentes variáveis do ambiente que integradas auxiliam na explicação da constituição daquilo que vemos. É a análise do todo, englobando fácies humanas, físicas e biológicas que apontam para a necessidade da execução de estudos de interpretação e explicação das diferentes fisionomias e relações existentes na natureza. Portanto é de fundamental importância na Geografia o estudo das diferentes fisionomias vegetais existentes. As classificações vegetais hoje utilizadas não abarcam toda a escala de associação de plantas existentes no planeta. Inseridas na Mata Atlântica, por exemplo, existem diversas formações vegetacionais que formam composições particulares, caracterizando assim uma paisagem totalmente diferenciada de seu entorno.

Para analisar a atual cobertura vegetal de uma dada área deve-se entender também seu histórico evolutivo ou sua paleogeografia. Esta análise auxilia na interpretação do comportamento que os indivíduos apresentam no presente e a forma como esse território se organiza. No âmbito regional, o Vale do Ribeira, que concentra grande riqueza natural, apresenta-se como um enorme laboratório para pesquisas.

Neste contexto, surge o interesse em identificar especificamente um tipo de vegetação diferenciada regional presente no Parque Estadual do Rio do Turvo (PERT), levantando as condicionantes para sua permanência. Trata-se de uma formação totalmente diferenciada do contexto geral da flora dominante, que se estende por cerca de 80 hectares (segundo estimativas da administração da unidade). O local, ainda sem descrição e classificação oficial, é denominado Campo do Veludo pela população da região devido a ocorrência significativa do musgo Sphagnum sp, conhecido popularmente como Veludo.

\section{ÁREA DE ESTUDO}

O PERT, conhecido até 2008 como Parque Estadual de Jacupiranga, localiza-se no Mosaico de Unidades de Conservação do Jacupiranga, estado de São Paulo. O Campo do Veludo localiza-se nos limites do município de Barra do Turvo com o estado do Paraná, no extremo sul do Estado de São Paulo, nas coordenadas S 24⒌'53.2" e W 048 13'52.0" (Figura 1). A área se encontra na cota média de 680 metros acima do nível do mar, no sopé 
da Formação da Serra do Cadeado, que chega a atingir 1.100 metros de altitude. O acesso ao campo se dá através de uma trilha de cerca de $9 \mathrm{~km}$ que parte da BR 116, no $\mathrm{km} \mathrm{524,} \mathrm{e}$ passa pelo interior de uma área de posse.

Figura 1 - Localização da área de estudo (Campo do Veludo) em relação ao município de Barra do Turvo e ao estado de São Paulo

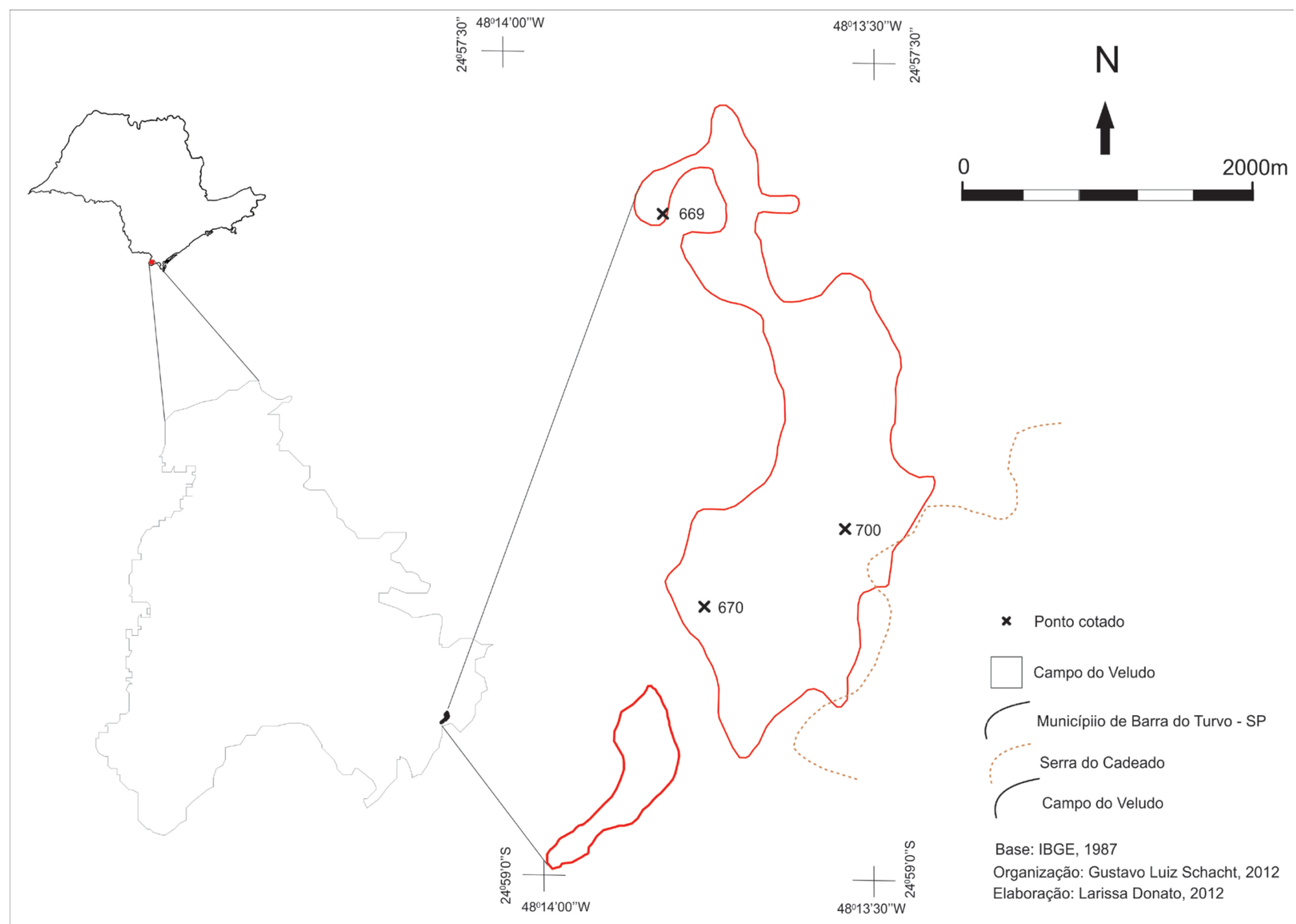

Org.: o autor.

Do ponto de vista da cobertura vegetal, no entorno do campo há uma clara predominância da Mata Atlântica (LIMA, 2005). Esta região é considerada a mais rica em recursos naturais do Estado de São Paulo pela grande concentração de unidades de conservação. Ainda segundo Peixoto e Gentry (1990) apud Tabarelli e Mantovani (1999), além do elevado grau de endemismo observado em alguns grupos de vegetais, a floresta atlântica apresenta elevada diversidade florística.

Sobre o relevo, Ross et al. (2007, p.4) consideram que:

A morfologia do relevo regional desenvolve-se na faixa do denominado Cinturão Orogênico do Atlântico, que apresenta uma elevada complexidade litológico-estrutural, fruto de longas e intensas atividades tectônicas de magnitude regional, que ocorreram no pré-cambriano médio e superior, com reativações tectogênicas de caráter epirogenético no Jura-Cretáceo e Cenozóico, associadas ao que Almeida (1967) denominou de reativação Wealdeniana. 
O relevo regional atual da área do parque é constituído de pequenas planícies, vales fluviais e um vasto conjunto serrano (composto pela Serra Gigante, Serra do Cadeado - Figura 2 - e pela Serra Guaraú), onde se localizam inúmeras cavernas (AGUIAR-DEDOMENICO, 2008). Na geologia, micaxistos e paragnaisses diversos representam os litotipos amplamente dominantes no Complexo Turvo-Cajati, embora intercalações de corpos de quartzito, mármore e rochas cálciossilicáticas, como no Campo do Veludo, sejam comuns (FALEIROS, 2008). Podemos classificar o Campo do Veludo como um Encrave Vegetacional, o qual segundo IBGE (1992, p.32), pode ser definido como "áreas disjuntas que se contatam", cercadas por regiões florística e fisionomicamente diferenciadas.

O Campo do Veludo apresenta-se na parte mais baixa do relevo, aos pés do conjunto da Serra do Cadeado, em uma pequena planície provavelmente oriunda de controle estrutural. A Figura 3 mostra a área, representada pela figura em branco e as elevações existentes em seu entorno, como a Serra do Cadeado. A costa encontra-se a cerca de 20 $\mathrm{km}$ a nordeste da área de estudo.

Esta pesquisa foi realizada, em parte, devido à falta de estudos das espécies presentes no Campo do Veludo e para a definição desta formação diferenciada, considerando sua fragilidade. É importante ressaltar que esta formação vegetal é única nos limites do parque, além de se tratar de um local visitado por pequenos grupos de estudantes. Podese considerar o local de fundamental importância para atividades de pesquisa e educação ambiental, que deve receber especial atenção por parte da administração do parque.

Figura 2- Transição de vegetação do tipo abrupta, sendo em primeiro plano, o Campo do Veludo, em segundo e terceiro planos, a formação arbórea do conjunto da Serra do Cadeado.

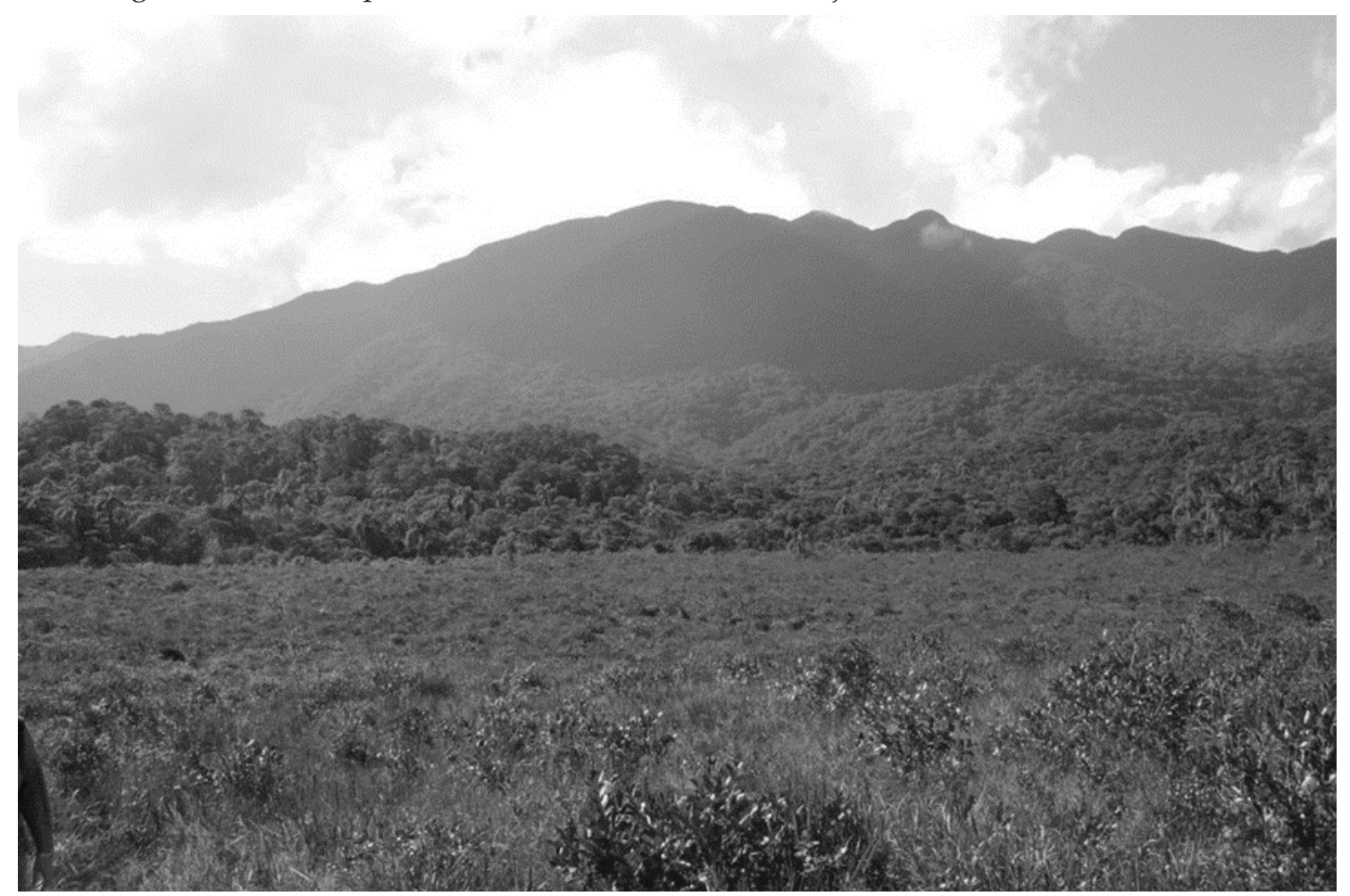

Foto: G. Schacht, 2008. 
Figura 3 - Hipsometria da área de estudo mostrando diferenças altitudinais significativas
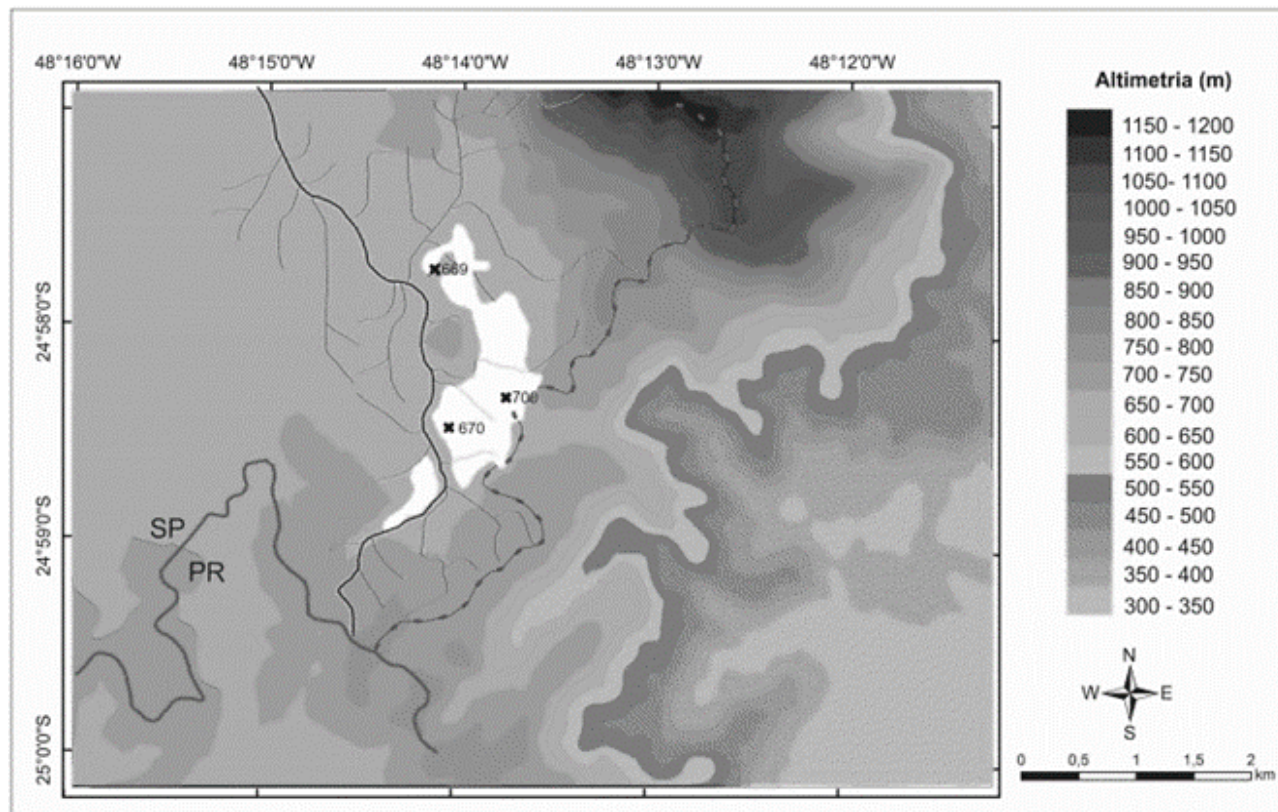

$\times$ Ponto cotado

Org.: o autor.

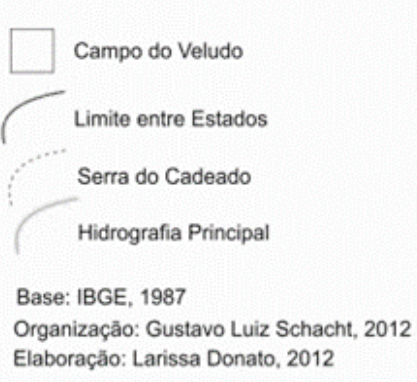

\section{MATERIAIS E MÉTODOS}

Para o desenvolvimento do estudo foi realizada uma revisão bibliográfica e posteriormente incursões a campo periódicas e quadrimestrais durante 16 meses para levantamento dos dados necessários, coleta de material botânico e amostras de solos. Durante o trabalho em campo foi realizada a caracterização geral da vegetação, mediante listagem das espécies ocorrentes, anotação do hábito e das características de cada uma delas bem como a produção do perfil de vegetação de um local representativo das peculiaridades da área de estudo, como as transições marcantes entre os tipos de vegetação presentes no local. Para a coleta, quando necessário, foi analisada a época de floração e frutificação das espécies conhecidas, sendo efetivamente coletadas somente as amostras que reunissem todas as características necessárias para seu completo reconhecimento segundo literatura específica. Foram utilizadas técnicas de manejo de coleções botânicas em campo para herborização (IBGE, 1992).

Como procedimento de coleta foi utilizado amostragem e coleta aleatória irrestrita (IBGE, 1992), para maior cobertura e detalhamento do local, observando o predomínio de determinadas espécies em local restrito (caráter finícola). O material botânico foi identificado em nível de família, gênero e, quando possível espécie, utilizando para isso bibliografia taxonômica especializada, comparação com fotografias, acervos já existentes, e, quando necessário, confirmação de especialistas.

Foi realizada também a investigação da cobertura pedológica para relacionar seus atributos químicos à formação vegetal, uma vez que foram observadas pequenas ilhas de vegetação arbórea onde se observa também uma diferenciação nos solos. Foram escolhidos quatro pontos de coleta e análise química de solo, segundo a morfologia local, como em 
área típica de campo, em área com influência de água a maior parte do ano, área seca o ano todo e em uma das ilhas de vegetação presentes. Sendo assim, optou-se por coletas com abertura de trincheiras e tradagens.

Foram duas tradagens: Pt 209 no interior de um dos cordões de vegetação nas coordenadas S 24058'05,9” e W 48¹3'52,1" aos 695 metros acima do nível do mar; Pt 208 em uma pequena elevação existente no campo, que não sofre em nenhum período a influência da água e localiza-se nas coordenadas S 24⒌'58,7' e W 48¹3'53,3" aos 698 metros acima do nível do mar. Foram feitas também duas coletas em trincheiras: Pt 190 (Amostras A, B

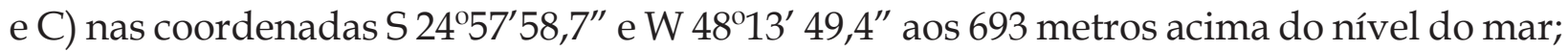
esta trincheira feita em solo pouco profundo, com $60 \mathrm{~cm}$ somente, está inserida no meio da formação típica do Campo do Veludo, porém com lençol freático aflorando na maior parte do ano. O segundo ponto de trincheira, Pt 205 (Amostras 1, 2, 3, 4, 5, 7, 8, 9, 10 e 11) localiza-se nas coordenadas $S$ 24 $57^{\prime} 89,7^{\prime \prime}$ e $W$ 48 $13^{\prime} 87,1^{\prime \prime}$ aos 677 metros acima do nível do mar, também recoberto por vegetação típica do campo.

\section{DESENVOLVIMENTO}

Juntamente com o clima e o solo, a vegetação é a indicação mais visível que temos de que estão ocorrendo, ou mesmo que já ocorreram, alterações na paisagem do planeta. As plantas são uma importante indicação do clima predominante em cada região e respondem muito rapidamente às mudanças que ocorrem em seu ambiente. A vegetação responde às mudanças se expandindo ou se retraindo, sendo que em cada fase climática, um tipo vegetal torna-se predominante, reduzindo ou mesmo extinguindo outras formas menos adaptadas à nova condição ambiental. Podem permanecer no ambiente algumas pequenas manchas de vegetação, que passam a serem denominadas relíquias vegetais ou encraves vegetacionais. Vale salientar que estas regressões e transgressões de formações vegetais influenciadas pelas alterações climáticas são lentas, persistindo em muitos locais, condições microclimáticas que desaceleram as mudanças na paisagem.

Saia (2006), estudando o Vale do Ribeira, e utilizando a datação com $\mathrm{C}_{14^{\prime}}$, mostra que no PETAR (Parque Estadual Turístico Alto Ribeira) e no PEI (Parque Estadual Intervales) entre 30 e 16 mil anos AP houve predomínio de clima seco e frio com ausência quase completa de indivíduos arbóreos, predominando a vegetação aberta de campos. Em suas conclusões, a autora afirma ainda que somente após 16 mil anos AP, é que houve a predominância de clima úmido e quente, com a retomada das espécies arbóreas ocorrentes hoje. Estes fatos fazem parte da Teoria dos Refúgios Florestais, que conforme Ab'Sáber (1988), trata-se de um dos mais importantes corpos de ideias referentes aos mecanismos padrões de distribuição de flora e fauna na América Tropical. O autor defende ainda que essa teoria, nascida de considerações sobre as flutuações climáticas do Quaternário na América do Sul e Central, constituiu-se numa das sérias tentativas de integração das ciências fisiográficas com as ciências biológicas, ocorridas depois do Darwinismo.

Ainda segundo Ab'Sáber (2003, p. 12), a Teoria dos Refúgios e Redutos: 
Trata-se, sobretudo, de floras que se aproveitaram da instabilidade das condições ecológicas das faixas de transição e contato, passando a dominar localmente o espaço, em subáreas onde as condições climáticas e ecológicas eram relativamente desfavoráveis para a fixação de padrões de paisagem diretamente filiados aos domínios paisagísticos contíguos, e pelo oposto, eram favoráveis ao adensamento e à expansão de determinadas floras.

A perda de umidade foi a maior alteração vinculada ao clima durante o período da última glaciação no atual território brasileiro. A redução de temperatura também foi sentida, entretanto ela foi significativa somente nas grandes latitudes e altitudes, onde houve redução suficiente para que as geleiras polares e de montanhas se expandissem (VIADANA, 2002)

Para Viadana e Cavalcanti (2006, p. 64):

A teoria dos refúgios florestais alega em síntese a ideia que, devido às flutuações climáticas da passagem para uma fase mais seca e fria durante o Pleistoceno terminal, as florestas tropicais ficaram retraídas às exíguas áreas de permanência da umidade, e constitui os refúgios como resultante deste isolamento.

No auge do último período glacial (de cerca de 120 até 18 mil anos AP), com a expansão das formações típicas de clima frio e seco, a vegetação ombrófila passou a ocupar locais restritos, como os fundos de vale, por exemplo, onde se concentrava a umidade, cedendo espaço para expansão das formações abertas, típicas e aclimatadas àquele momento climático. Do mesmo modo ocorreu com o retorno da tropicalidade, onde as formações abertas passaram a se concentrar somente em locais que detinham condições de microclima ideais para a sua manutenção.

Para Ab'Sáber (1988, p. 26):

A teoria dos refúgios diz respeito, sobretudo, à identificação dos momentos de maior retração das florestas tropicais, por ocasião da desintegração de uma tropicalidade relativa preexistente. Nessa contingência, massas de vegetação outrora contínuas, ou mais ou menos contínuas, ficaram reduzidas a manchas regionais de florestas, em sítios privilegiados, à moda dos atuais "brejos" que pontilham o domínio das caatingas, nos sertões do Nordeste. Os refúgios florestais pleistocênicos seriam os setores de mais demorada permanência da vegetação tropical e de seus acompanhantes faunísticos - em forte competitividade - durante os principais períodos de retração das condições tropicais úmidas. [...]

Não só as formações de Cerrado e Caatinga tiveram êxito em sua expansão em períodos glaciais, como também as formações abertas atuais de campos com araucárias vinculadas, no sul do Brasil, restingas e mesmo as formações campina e campinarana, que ocorrem em pontos isolados na Amazônia, além dos atuais brejos existentes no nordeste brasileiro. Estas formações na paisagem atual estão disjuntas, em discordância com a formação florestal tropical típica. 
Além das condicionantes climáticas pretéritas que geraram as condições para instalação das formações diferentes das atuais, interferem diretamente na manutenção atual destas espécies vegetais as características do local onde se desenvolvem os indivíduos. Na área de estudo, um dos principais limitantes de desenvolvimento de algumas espécies florestais do entorno é a inundação periódica recorrente, acarretando um processo adaptativo e seletivo dos indivíduos.

No período chuvoso no Vale do Ribeira, na área de estudo estão ausentes determinadas espécies devido ao seu tamanho e condições de desenvolvimento. Exemplo significativo desse fato é Drosera sp, e os líquens Cladonia sp e Parmelia sp. Em se tratando de plantas de pequeno porte, todos com poucos centímetros, são recobertos pela água e passam possivelmente a compor o banco de germoplasma no período de novembro a março. Após este período, estas espécies retornam à paisagem, ao mesmo tempo em que a Quaresmeira-daserra (Tibouchina candolleana) e outras, tendem a desaparecer temporariamente. Nos poucos pontos onde existe uma elevação no relevo, os solos são mais profundos e apresentam coloração avermelhada indicando que não possuem concentração de água na superfície em nenhuma época do ano. Este ponto de estudo apresenta vegetação herbáceo-arbustiva baixa com exemplares de até 1,40 metros nos locais mais característicos do campo; nos pontos de solo mais profundo, alguns exemplares podem atingir até 4 metros de altura.

No campo típico, a espécie vegetal de maior ocorrência é o araçá-amarelo (Psidium cattleianum DC) - Figura 4 - frutificado, porém nanificado em relação ao seu porte em formações mésicas presentes em formações litorâneas (CONAMA, 1996). Esta espécie é responsável quase exclusivamente pelo extrato arbustivo do campo, juntamente com algumas poucas espécies.

Figura 4 - Associação predominante no Campo do Veludo, - Psidium, Sphagum e Cladonia - em trecho que permanece alagado em parte do ano. Ao fundo, transição abrupta para vegetação de porte arbóreo típica da Mata Atlântica

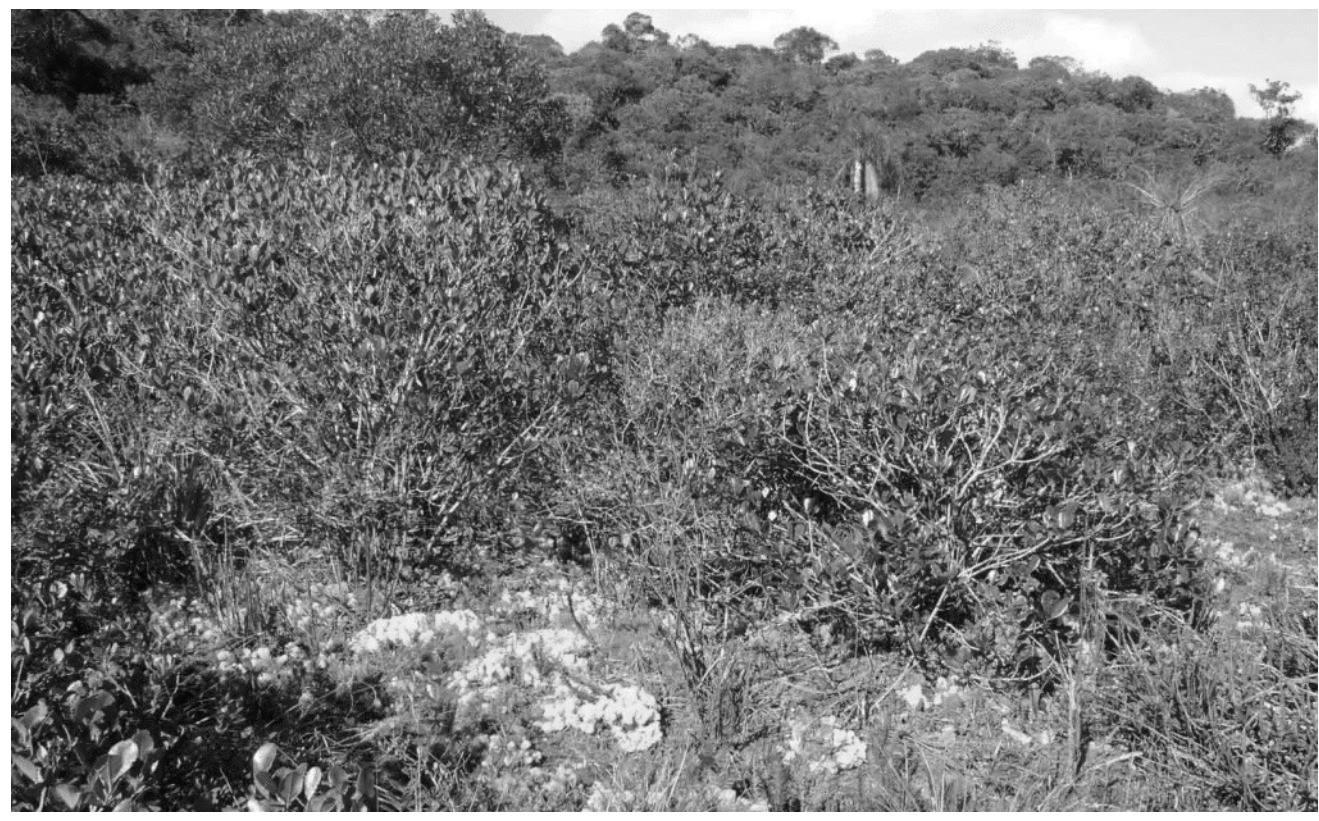

Foto: G. Schacht, 2008. 
O esfagno (Sphagnum sp) se desenvolve encobrindo quase totalmente o solo. No inverno, com menor precipitação, se restringe aos locais com incidência de sombra e umidade, bem como sob Psidium cattleianum. Os grandes bancos de Sphagnum sp., antes vicejantes, se desidratam e aguardam o período chuvoso. O efeito de sua dominância é uma cobertura orgânica não consolidada sobre um solo incipiente de perfil turfoso.

A área de estudo também é recoberta pelo fofão (Cladonia sp), igualmente restrito aos ambientes de maior umidade, bem como pela planta carnívora (Drosera sp), comum em terrenos úmidos e sistemas de dunas costeiras úmidas e de elevada acidez edáfica (CORDAZZO; SEELIGER, 1995). Estas são as principais espécies que caracterizam o campo e estão presentes em quase toda sua extensão.

Ocorrem também na área subarbustos do gênero Baccharis sp., utilizado na medicina popular (carqueja), e que se desenvolvem como fixadora de terrenos arenosos, ocorrendo em diversos tipos de terreno (CORDAZZO; SEELIGER, 1995). A carqueja apresenta-se no campo somente em período mais úmido do ano (novembro - março). Nestes períodos úmidos também se pode encontrar a Quaresmeira-da-serra (Tibouchina candolleana), florida, a qual no interior do campo atinge altura máxima de $40 \mathrm{~cm}$, enquanto na formação florestal adjacente se destaca como um indivíduo arbóreo. No período mais seco (abril - outubro) estes indivíduos desaparecem da paisagem.

Outras espécies de ocorrência menos comum no campo são botão-de-ouro (Xyris jupicai) no solo úmido e palmeira-jerivá (Syagrus romanzoffiana) em algumas ilhas de solo mais profundo. Secundariamente ocorrem bromélias do gênero Vriesea sp e Bromelia antiacantha, alguns indivíduos do gênero Cycas e orelha-de-onça (Tibouchina grandifolia). A gramimunha (Weinmania humilis), planta popular em ambientes de altitude e mesmo florestas de Araucária no Rio Grande do Sul, é mais frequente no trecho de transição gradual entre o campo do veludo e vegetação atlântica, dominando o extrato arbóreo baixo com indivíduos de cerca de 4 metros de altura.

São encontradas também espécies do gênero Lycopodium sp, que ocorrem em terrenos arenosos úmidos e dunas costeiras (CORDAZZO; SEELIGER, 1995), além do gênero de líquen Parmelia sp, característico de áreas úmidas, todos pertencentes ao consórcio comum no Campo do Veludo, além da Camarinha (Myrcia sp), de comum ocorrência em ecossistemas litorâneos de dunas (CONAMA, 1996), e o capim-navalha (Hypolytrum sp.), em alguns pontos.

A seguir é apresentado o perfil fitogeográfico e topográfico de um transecto da área estudada (Figura 5), apresentando os diferentes consórcios de vegetação existentes, além do agrupamento de solos segundo suas características principais, sem delimitação exata de profundidade.

Em relação à geologia local, percebe-se que a cobertura do campo é predominantemente de Quartzito, que combinado com os sedimentos recebidos das áreas mais elevadas de entorno formam solos bastante característicos. Estes possuem textura arenosa nos horizontes superficiais, proveniente da alteração das rochas de seu entorno, com o predomínio do Quartzito. Nos horizontes intermediários, predominam em alguns locais solos mais siltosos, com presença de intercalações de areia grossa nos horizontes inferiores. 
Figura 5 - Perfil Topo e Fitogeográfico da área estudada, mostrando além dos consórcios de vegetação existentes no local

\section{Perfil Topo e Fitogeográfico}

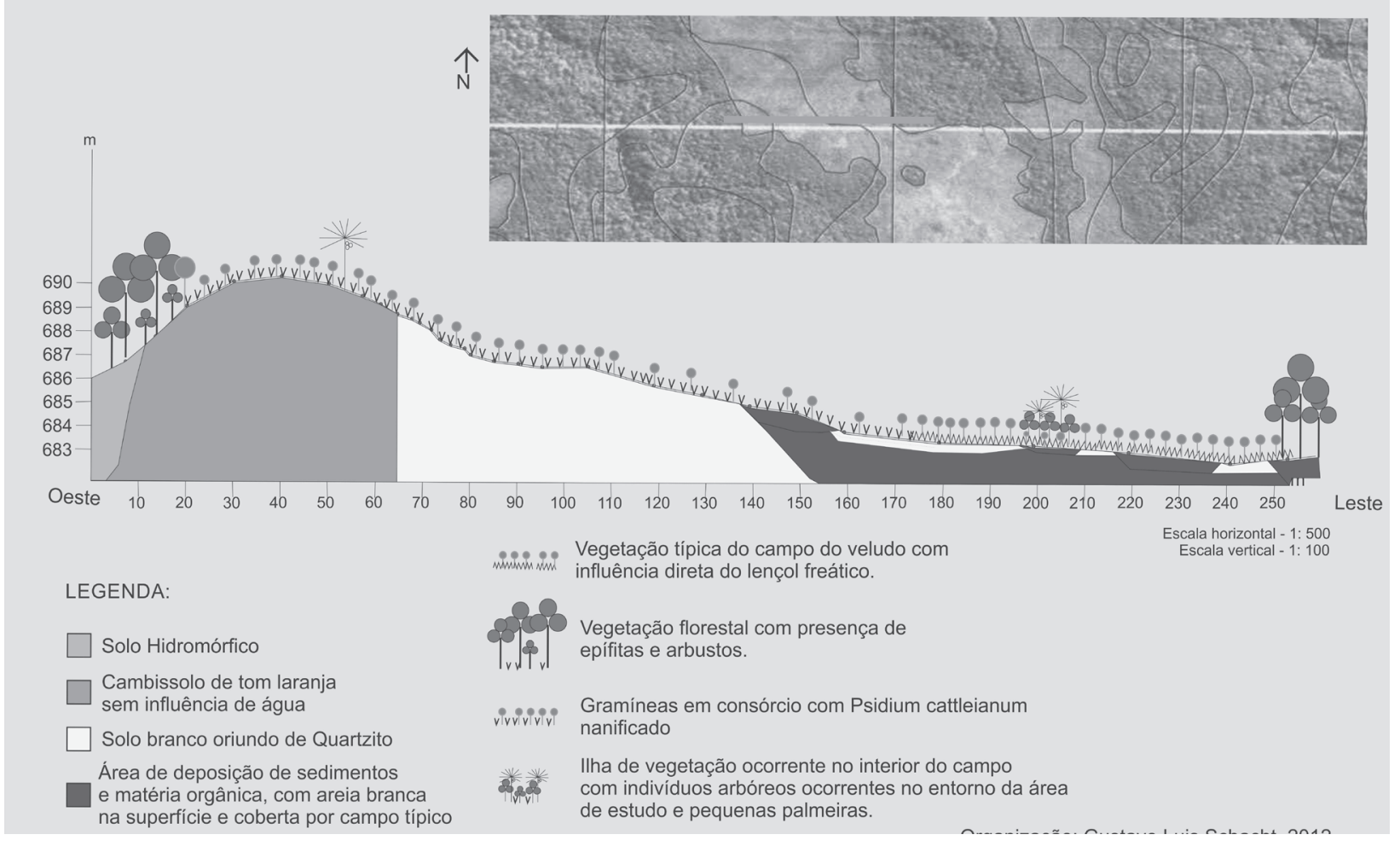

Org.: o autor.

Ao avaliar os diferentes tipos de solos encontrados no Campo do Veludo, foi encontrado em um dos perfis, um horizonte B espódico aos $30 \mathrm{~cm}$ composto de uma capa de aproximadamente $10 \mathrm{~cm}$ de espessura, bastante endurecida. Esta formação é encontrada nas partes mais baixas do campo, onde ocorre acúmulo de água. Percebe-se que as plantas têm dificuldades em lançar seu sistema radicular pivotante e o crescimento radicular em forma de cabeleira (fasciculada) limita a altura dos indivíduos.

Já nas poucas áreas que circundam ou penetram no Campo do Veludo, como os cordões de vegetação, onde o solo teve desenvolvimento quartzarênico, as espécies ocorrentes são aquelas pertencentes à floresta do entorno e não da área central do Campo, com indivíduos de porte arbóreo. Estes solos mais profundos permitem a formação de pequenos corredores (cordões) que recortam a área de estudo dividindo-a em "pedaços", fazendo com que a vegetação nanificada presente forme ilhas de vegetação que se destacam na paisagem, intercaladas com a vegetação desenvolvida nos cordões que se expandem sobre o campo. A transição entre o campo e a floresta do entorno, na maior parte da área de estudo, é também abrupta, não existindo limites nítidos na superfície. 
Tabela 1 - Resultado da análise de macronutrientes dos solos da área estudada

\begin{tabular}{|c|c|c|c|c|c|c|c|c|c|c|c|}
\hline \multirow{3}{*}{$\begin{array}{c}\text { Amostra } \\
205 / 1\end{array}$} & \multirow{3}{*}{$\begin{array}{c}\text { Horizonte } \\
\text { (cm) } \\
0-7\end{array}$} & \multirow{3}{*}{$\begin{array}{c}\mathbf{P H}\left(\mathrm{CaCl}_{2}\right) \\
3,4\end{array}$} & \multirow{2}{*}{\multicolumn{2}{|c|}{$\begin{array}{l}\text { Mat. Orgânica Carbono } \\
\mathrm{g} / \mathrm{dm} 3\end{array}$}} & \multirow{3}{*}{$\begin{array}{c}\text { Fósforo } \\
\mathrm{mgP} / \mathrm{dm}_{3} \\
4,36\end{array}$} & \multirow{3}{*}{$\begin{array}{c}\text { Potássio } \\
0,11\end{array}$} & \multirow{3}{*}{$\begin{array}{l}\text { Cálcio } \\
0,51\end{array}$} & \multirow{2}{*}{\multicolumn{3}{|c|}{$\begin{array}{c}\text { Magnésio } \mathbf{H}^{+}+\mathrm{Al}^{+3} \text { Alumínio } \\
\mathrm{cmol}_{\mathrm{c}} / \mathrm{dm}^{3}\end{array}$}} & \multirow{3}{*}{$\begin{array}{c}\begin{array}{c}\text { Capacidade } \\
\text { de troca }\end{array} \\
8,44 \\
\end{array}$} \\
\hline & & & & & & & & & & & \\
\hline & & & 91,73 & 53,21 & & & & 0,34 & 7,48 & 1,05 & \\
\hline $205 / 2$ & 8-16 & 3,3 & 70,13 & 40,68 & 5,34 & 0,04 & 0,33 & 0,21 & 8,68 & 1,15 & 9,26 \\
\hline $205 / 3$ & $17-22$ & 3,2 & 70,31 & 40,78 & 3,29 & 0,02 & 0,28 & 0,21 & 10,07 & 1,3 & 10,58 \\
\hline $205 / 4$ & $23-26$ & 3,2 & 49,75 & 28,86 & 2,22 & 0,02 & 0,66 & 0,38 & 8,68 & 1,2 & 9,75 \\
\hline $205 / 5$ & $27-30$ & 3,1 & 41,98 & 24,35 & 1,33 & 0,01 & 0,28 & 0,17 & 16,33 & 3,25 & 16,79 \\
\hline $205 / 6$ & $31-36$ & 3,4 & 23,49 & 13,63 & 1,16 & 0,01 & 0,64 & 0,3 & 9,01 & 2,75 & 9,96 \\
\hline $205 / 8$ & $37-41$ & 3,6 & 43,01 & 24,95 & 1,6 & 0,01 & 0,15 & 0,09 & 11.68 & 2,8 & 11,93 \\
\hline $205 / 9$ & $42-77$ & 3,7 & 60,12 & 34,87 & 3,11 & 0,01 & 0,18 & 0,09 & 13,07 & 4,15 & 13,34 \\
\hline $205 / 10$ & 56 & 3,9 & 38,18 & 22,14 & 3,38 & 0,01 & 0,18 & 0,13 & 10,07 & 2,7 & 10,39 \\
\hline $205 / 11$ & $78-83$ & 3,8 & 21,07 & 12,22 & 3,38 & 0,01 & 0,28 & 0,17 & 10,07 & 2,75 & 10,53 \\
\hline 208 & $40-60$ & 4,5 & 9,16 & 5,31 & 0,71 & 0,02 & 0,38 & 0,17 & 2,74 & 0,35 & 3,31 \\
\hline 209 & $40-60$ & 5,8 & 16,58 & 9,62 & 1,07 & 0,03 & 3,31 & 1,61 & 2,11 & 0 & 7,07 \\
\hline A & $0-20$ & 3,5 & 14,7 & 8,53 & 2,49 & 0,04 & 0,26 & 0,13 & 3,97 & 0,7 & 4,39 \\
\hline B & $21-40$ & 3,8 & 11,59 & 6,72 & 1,69 & 0,01 & 0,31 & 0,17 & 9,35 & 2,3 & 9,84 \\
\hline $\mathrm{C}$ & $41-60$ & 3,5 & 20,26 & 11,75 & 1,78 & 0,01 & 0,26 & 0,13 & 10,07 & 1,85 & 10,46 \\
\hline $\begin{array}{r}\text { Amostra } \\
\text { perfil con } \\
\text { metros de a } \\
/ \text { Amo }\end{array}$ & tude. / An & 209 refer & tradagem re & Tit & vegeta & senvo & em S & "05,9" & $\begin{array}{l}0 \\
0 \\
0\end{array}$ & los 695 met & $\begin{array}{l}\text { trata-se de de } \\
53,3 " \text { aos } 698 \\
\text { tros de altitude. } \\
\text { le altitude. }\end{array}$ \\
\hline
\end{tabular}

Org.: o autor.

Os solos em geral apresentam um elevado nível de acidez, com $\mathrm{pH}$ variando entre 3,1 e 5,8, o que indica solo extremamente seletivo para o desenvolvimento de espécies, com exceção do P 209, que apresenta pH pouco mais alto, de 5,8. Este ponto é o que comporta a vegetação de porte arbóreo presente no campo. As amostras do ponto P 205 também são as que apresentam maior diferenciação se comparados os níveis de alumínio e matéria orgânica em relação aos demais pontos. Deste modo observa-se que nas análises pedológicas feitas em terrenos que suportam vegetação típica do Campo do Veludo, há um caráter de desequilíbrio de nutrientes típicos de um solo não agricultável e elevado índice de alumínio, que interfere diretamente no desenvolvimento das plantas do local de diversas formas, selecionando aquelas mais resistentes a este componente e dificultando muitas vezes a absorção do potássio, o qual influi no crescimento dos indivíduos. Outra condicionante importante para o controle do desenvolvimento da vegetação local é o horizonte espódico encontrado em boa parte do campo aos $35 \mathrm{~cm}$ de profundidade (Figura 6). Ao avaliar especificamente esta faixa de aproximadamente $10 \mathrm{~cm}$ de espessura, observa-se um acúmulo de partículas arenosas que formam agregado endurecido, onde a água encontra dificuldade na penetração. Observando a trincheira também é possível ver que as raízes se desenvolvem somente acima desta camada, indicando grande controle sobre o desenvolvimento das plantas. 
Figura 6 - Trincheira aberta em ambiente típico do Campo do Veludo (P 205) com destaque para a camada espódica esbranquiçada presente

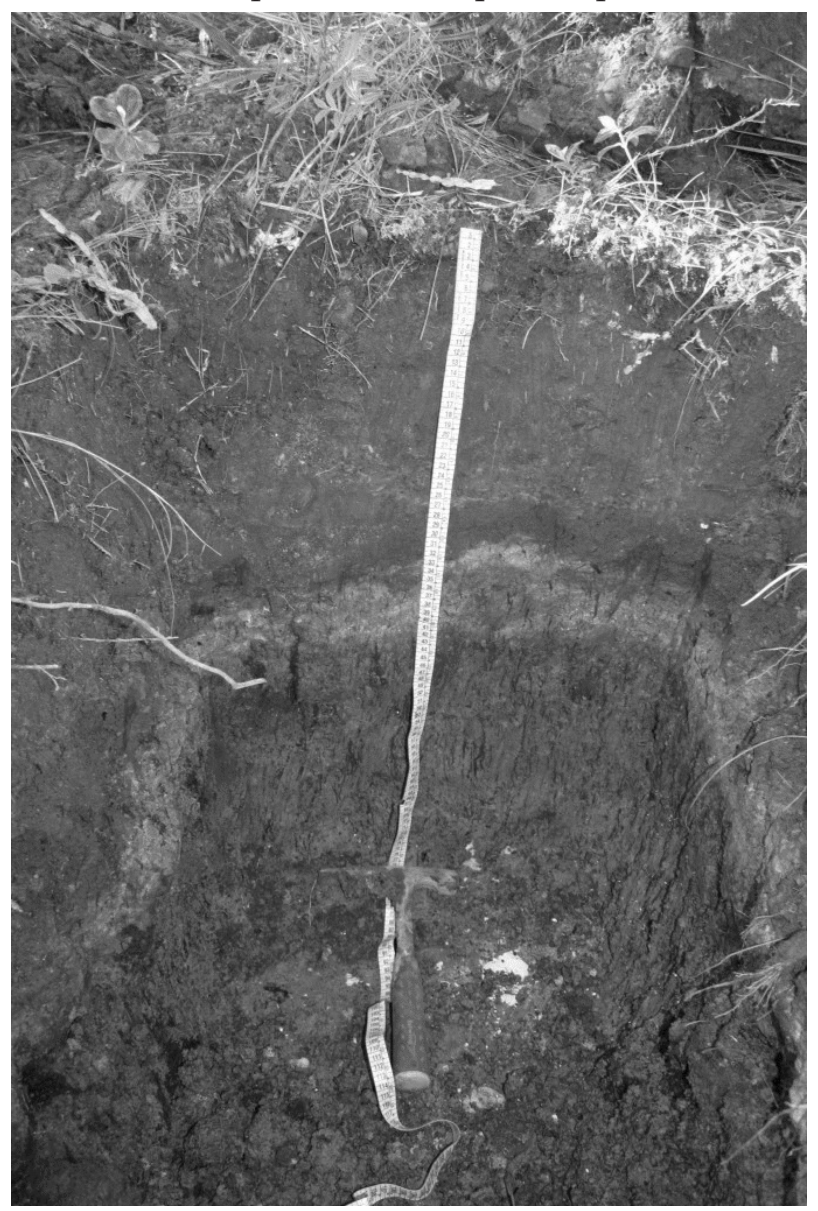

Foto: G. Schacht, 2009.

\section{CONCLUSÃO}

Os solos constituem o principal fator responsável para a distribuição atual da vegetação do Campo do Veludo. Os baixos valores de $\mathrm{pH}$ indicam que a elevada acidez seleciona as plantas que ali irão se fixar; os altos índices de alumínio também tem relação direta com a cobertura vegetal, pois interferem no funcionamento e desenvolvimento da planta, imprimindo aspecto diferenciado em tamanho, com desenvolvimento de troncos tortuosos devido à oligotrofia.

Os locais de solo mais profundo e de combinações químicas mais próximas ao ponto de equilíbrio das plantas, formam linhas que evoluem e se estendem sobre o campo, isolando em parte a vegetação nanificada do Campo do Veludo. Embora os solos tendam a evoluir e começar a reunir características químicas e físicas que certamente alterarão a fisionomia da vegetação local, as limitações impostas pela matriz rochosa de Quartzito próxima à superfície deverão retardar as alterações da paisagem.

Biogeograficamente, acredita-se que a ocorrência das espécies diferenciadas pode estar ligada a paleoambientes mais áridos e o Campo de Veludo pode ser inicialmente 
denominado como Relíquia/Encrave de vegetação nanificada sobre Quartzito, ou Campo sobre Quartzito, sob controle edáfico.

Interferências no processo de evolução podem causar a extinção deste tipo de vegetação. Neste contexto, o local, que não é utilizado hoje para atividade de educação ambiental, ou mesmo pesquisa científica, deve receber destaque no plano de manejo como área de extrema fragilidade ambiental. Devem-se empreender estudos mais aprofundados acerca de sua gênese e evolução.

Suas características permitem que o Campo seja incluído na categoria nominada por Ab'Sáber (2008) como Paisagem de Exceção. Neste contexto o referido autor coloca as formações litorâneas (citando o litoral sul do Estado de São Paulo) como uma paisagem de exceção, tendo em vista a dificuldade em se entender suas características gerais e sua complexidade.

Desta maneira sustentamos a hipótese de que o Campo do Veludo pode ser classificado como uma relíquia vegetal resultante de condições paleoclimáticas recentes, somado às condições pedológicas e geomorfológicas do local que se insere para sua manutenção atual.

\section{REFERÊNCIAS}

AB'SABER, Aziz Nacib. O Pantanal Mato-Grossense e a Teoria dos Refúgios. Revista brasileira de Geografia, Rio de Janeiro, v.50, n. 2, p. 9-57, 1988.

Os domínios de Natureza no Brasil: Potencialidades Paisagísticas. São Paulo: Ateliê Editorial, 2003.

Brasil, Paisagens de Exceção: o litoral e o Pantanal Mato-grossense: patrimônios básicos. Cotia: Ateliê Editorial, 2008.

CONAMA. Resolução CONAMA, n. 7 de 23 de julho de 1996. Disponível em: <http:/ /www.bvsde.paho. org/bvsacd/cd38/Brasil/R07-96.pdf> Acesso em: 13 jan. 2011.

AGUIAR-DE-DOMENICO, Eleonora. Herpetofauna do Mosaico de Unidades de Conservação do Jacupiranga. São Paulo, 2008. Dissertação (Mestrado em Zoologia) - Universidade de São Paulo.

CORDAZZO, César Vieira; SEELIGER, Ulrich. Guia ilustrado da vegetação costeira no extremo sul do Brasil. 2.ed. Rio Grande: FURGS, 1995.

FALEIROS, Frederico Meira. Evolução de terrenos tectono-metamórficos da Serrania do Ribeira e Planalto Alto Turvo (SP, PR). São Paulo, 2008. Tese (Doutorado em Geoquímica e Geotectônica) - Universidade de São Paulo.

IBGE - Instituto Brasileiro de Geografia e Estatística. Manual técnico da vegetação brasileira. Rio de Janeiro, 1992. (Manuais Técnicos em Geociências, 1).

LIMA, André Penin Santos de. Análise dos processos formativos do Sítio Capelinha: estabelecimento de um contexto microrregional. São Paulo, 2005. Dissertação (Mestrado em Arqueologia) - Universidade de São Paulo.

ROSS, Jurandyr Luciano Sanches et al. Relatório de pesquisa e mapeamento Geomorfológicodo Parque Estadual Intervales - Fundação Florestal do Estado de São Paulo; subsidio ao plano de manejo do Parque Estadual Intervales. Departamento de Geografia: Laboratório de Geomorfologia. São Paulo, 2007. Disponível em: <http:// www.fflorestal.sp.gov.br/.../05\%20Relatorio $\% 20$ Geomorfologia $\% 20 \mathrm{e} \% 20$ Fragilidade.pdf> Acesso em: 13 jul. 2009.

. Geomorfologia: ambiente e planejamento. 8.ed. São Paulo: Contexto, 2007. 
TABARELLI, Marcelo; MANTOVANI, Waldir. A riqueza de espécies arbóreas na floresta atlântica de encosta no Estado de São Paulo (Brasil). Revista Brasileira de Botânica, São Paulo, v. 22, n. 2, p. 217-223, ago. 1999.

SAIA, Soraya Elaine Marques Gouveia. Reconstrução paleoambiental (vegetação e clima) no Quaternário tardio com base em estudos multi/interdisciplinar no Vale do Ribeira (sul do estado de São Paulo). Piracicaba, 2006.Tese (Doutorado em Ciências) - Universidade de São Paulo.

VIADANA, Adler Guilherme. A teoria dos refúgios florestais aplicada ao estado de São Paulo. Rio Claro: ed. do autor, 2002.

VIADANA, Adler Guilherme; CAVALCANTI, Agostinho Paula Brito. A teoria dos refúgios florestais aplicada ao estado de São Paulo. Revista da Casa da Geografia de Sobral, v. 8 / 9, n 1, p. 61 - 80, 2006 / 2007. 